\title{
PENGARUH PENGKAJIAN KEWIRAAUSAHAAN DAN PENGIKLANAN TERHADAP PENCIPTAAN PENGHASILAN PADA IBU PKK KECAMATAN CEMPAKA PUTIH CIPUTAT
}

\author{
Fahmi Susanti \\ dosen02024@unpam.ac.id
}

Dosen Fakultas Ekonomi Universitas Pamulang

ABSTRAK

Goal ahir yang ingin digapai agar menemukan pengaruh Pengkajian kewirausahaan serta pengiklanan terhadap penciptaan penghasilan pada Ibu PKK Kecamatan Cempaka Putih Ciputat, dengan cara partial atau simultan / bersama- sama . Dalam penyusunan penelitian memakai metode penelitian deskriptif kuantitatif. Dengan responden sebanyak113,cara pengambilan sampel secara sampel yang jenuh setiap responden mendapat kesamaan dalam peluang. Dianalisis dengan metode regresi linier ganda. Hasil uji hipostesis untuk pengkajian kewirausahaan dan pengiklanan

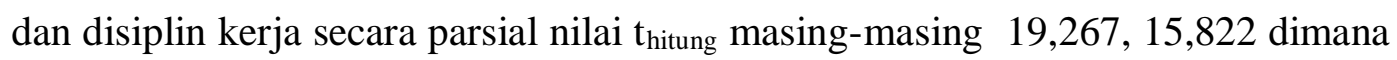
semua nilai $t_{\text {hitung }}>t_{\text {tabel. }}$. Untuk pengaruh bersama- sama diperoleh $F_{\text {hitung }}>F_{\text {tabel }}$ yaitu 145,428 $>2,46$. Taraf signifikansinya $\alpha=0,05$. Maka dapatlah disimpulkan bahwasanya pengkajian kewirausahaan dan pengiklanan secara parsial maupun bersama- sama berpengaruh signifikan terhadap penciptaan penghasilan. Dengan persamaan regresi linier $\hat{\mathrm{Y}}=0,189+0,254 \mathrm{X}_{1}+0,167 \mathrm{X}_{2}$ artinya pengkajian kewirausahaan dan pengiklanan mempunyai kemampuan untuk mempengaruhi penciptaan penghasilan. Nilai koefisien determinasi 0,928 atau $92,8 \%$ menjelaskan bahwasanya pengkajian kewirausahaan serta pengiklanan punya kemampuan 92,8\% untuk mempengaruhi penciptaan penghasilan sisanya $7,2 \%$ terdapat pada pengaruh dari variabel bebas lain yang tidak diteliti.

Kata Kunci: kewirausahaan, pengiklanan, penciptaan penghasilan

\section{ABSTRACT}

The reseacrh was aimed to determinate the influence of enterpreunership and advertising towards the increased income on PKK's member at Cempaka Putih sub-district, Ciputat partially or simultaneously.The research used "descriptive quantitative" method. The respondent of the research was analysed with regression double linier method. The result of hipotheses experiment of the research was thitung was 19,267; 15,822 which meant all thitung > ttable. Fsignificant level was $a=0,05$. The conclusion was the enterpreunership and advertising partially or 
simultaneously towards affecting the increased income. The remaining 7,2\% was found in the effect of the independent variable that was not in the research. or simultaneously had affected employee's performance significantly. The equqtion of segression double linier $Y=0.189+0.254 X 1+0.167 X 2$, that meant the research of enterpreunership and advertising had effect towards the increased income. The value of determination coefficient was 0,928 or 92,8 persen, it meant the enterpreunership, advertising was found in the effect of the independent variable that was not in the researchanother influence from other free-variables which's not included to this reseach.

\section{Keywords: enterpreunership, advertising, increased income}

\section{PENDAHULUAN}

\section{A. Latar Belakang}

Kepegawaian yaitu hal terpuncak di suatu badan. Hal pokok yang menentukan hasil kerja badan bisnis yaitu kualitas manusianya. Dengan perkembangan pebisnis dengan semakin tingginya kualitas petugas diharapkan semakin tinggi eksis badan usaha pebisnisan. Pengiklanan menjadi fokus perhatian yang sangat utama dalam pengembangan bonafit atau tidaknya serta predikat pebisnis. Melalui pengiklanan didapatkan berbagai kelebihan yaitu : mengenalkan serta menyampaikan jenis hasil yang ditujukan kepada sekumpulan individu, serta sekumpulan masyarakat secara meluas. Pengkajian berwirausaha bermaksud memberikan bantuan untuk menggali, menegakkann, serta meelstarikan kekuatan atau bakat usaha mandiri, dengan muara ahir bisa memunculkan penghasilan baru hingga terjadi kenaikan ekonomi rumah tangga.

\section{B. Perumusan Masalah}

1. Besaran pengaruhnya antara pengkajian wirausaha dengan penciptaan penghasilan?

2. Besaran pengaruhnya antara Pengiklanan dengan penciptaan penghasilan?

3. Besaran pengaruhnya antara pengkajian wirausaha serta Pengiklanan dengan cara (bersama-sama) dengan penciptaan penghasilan?

\section{Pembatasan Masalah}

Disini dilakukan pemfokusan diantaranya yaitu yang akan dibahas: "pengkajian wirausaha, pengiklanan, penciptaan penghasilan ibu PKK Kelurahan Cempaka Putih Ciputat.

\section{Tujuan Penelitian}

Harapannya dapat menjawab hal-hal terkait yaitu:

1. Diketahui pengaruh antara pengkajian kewirausaahan terhadap penciptaan penghasialn

2. Diketahui pengaruh antara pengiklanan terhadap penciptaan penghasilan. 
3. Diketahui pengaruh pengkajian kewirausahaan serta pengiklanan secara bersama/simultan terhadap penciptaan penghasilan .

\section{TINJAUAN PUSTAKA}

\section{A. Manajemen}

Jika dilihat dari proses tercapainya keputusan sampai tercapainya hasil pekerjaan badan usaha, teknik pengelolaan lah yang mempunyai andil sangat penting. Pengelolaan lebih focus pada bagian pengarahan dalam berbagai perencanaan sampai tingkat control(evaluasi) hasil kerjaan dengan muara ahir tercipta keeksisan serta makmurnya badan usaha pebisnis. Penguraian "SP.Hasibuan (208:50)

Pelaksanaan di dalam pengelolaan merupakan terstrukturnya pengetahuan dengan berurutan terdiri dari kreatifitas seni keterampilan dalam mengkaryakan berbagai sumber daya anggotanya serta sumber daya lainnya de maksud dicapainya goal kegiatan."

\section{B. Manajemen SDM}

Menjadi sebidang ilmu yang serta berkembang guna memk pemahaman mendalam, panda secara menyeluruh pengambilan ahir keputusan : sebagai masukan dari pi penyusunan struktur, angg: kebijakan, prosedur serta progi disini yang berperan set subyeknya yaitu manusia.

\section{Pengkajian}

Adalah kegiatan yang berpı dalam penguraian suatu "kompo..... untuk diketahuinya kondisi secara mendalam serta secara detail. Penguraian Effendi (1995) pengkajian adalah proses dalam penguraian suatu komponen untuk diketahuinya kondisi terkini secara dalam dan detail. Sisi keadaan yang didalami di pengkajian yaitu mengumpulkan data-data terkait berusaha secara mandiri, berbagi informasi serta berita-berita agar diketahuinya kondisi terkini, mengenalkan masalah-masalahnya ,mengenalkan bagaimanakah kelebihan serta kekurangannya

\section{Pengiklanan}

Menjadi fokus perhatian yang sangat utama dalam pengembangan bonafitnya / predikat pebisnis. Melalui pengiklanan didapatkan berbagai kelebihan yaitu : mengenalkan serta tersampainya informasi terkait jenis hasil barang / jasa yang ditujukan kepada individu, golongan masyarakat secara meluas. Penguraian

\section{E. Kerangka Pemikiran}

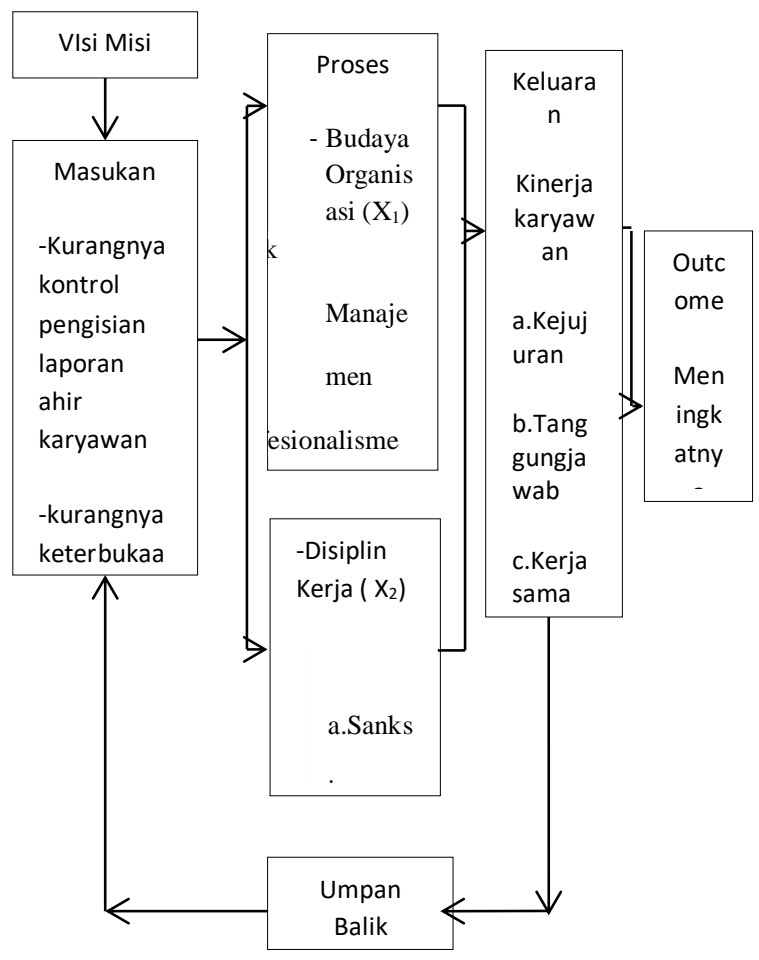




\section{Gambar 2.1 : Kerangka Pemikiran} Penelitian

\section{F. Hipotesis Penelitian}

Mengacu kepada model penelitiannya yaitu:

1. Variabel Pengkajian memiliki pengaruh baik yang sangat berarti kepada penciptaan penghasilan.

2. Variabel Pengikanan memiliki pengaruh baik yang sangat berarti kepada penciptaan penghasilan.

3. Variabel Pengkajian dan Pengiklanan memiliki pengaruh baik yang sangat berarti kepada penciptaan penghasian.

\section{METODE PENELITIAN}

\section{A. Tempat, Waktu}

Dilakukan di Kelurahan Cempaka Putih Ciputat, berlangsung sejak Oktober 2018 selesai Januari 2019.

\section{B. Metode Penelitian}

Disini mengambil sampel secara langsung dari "populasi". Metodenya (deskriptip kuantitatif). Dengan harapan dapat diketahui pengaruhnya Pengkajian, Pengiklanan, dengan penciptaan penghasilan. Penguraian "Sugiyono (2007:13) penelitian yang memiliki goal ahir melakukan uji kembali "hipotesis". Data dikumpulkan dengan alat instrument, penganalisaan data yang dipakai dalam meneliti responden beserta sampel. Sifatnya dengan penghitungan angka (kuantitatif)

\section{Populasi dan Sampel 1.Populasi}

Adalah semua obyek, seluruh gejala dan segala kejadian atau peristiwa yang akan dipilih seaarta harus sesuai dengan masalah yang akan diteliti, Hadi (2012:75). Populasi dalam penelitian ini adalah Ibu PKK Cempaka putih Tahun 2018 sebanyak 113orang.

\section{Sampel}

Merupakan domain / bagian suatu objek serta subjek yang menjadi wakil dari jumlah serta karakteristik karakteristik dan sudah dilakukan penetapan. Penguraian "Sugiyono (2011:157). Domain Populasi dalam penelitian ini adalah Ibu PKK Kelurahan Cempaka Putih Ciputat sebanyak 113 orang.

\section{Teknik Penentuan Data}

Data primer serta sekunder dikatakan sebagai sumber dalam teknik mengambil data .

\section{E. Metode Analisis Data}

1. Uji Validitas

Peneliti memakai "korelasi Product moment" ini dipakai dalam melakukan pengukuran kesahan kuesioner.

\section{Uji Reliabilitas}

Pengujian yang berkaitan dengan konsistensi dan stabilitas data atau temuan, "Sugiyono (2011: 268)."

\section{3 . Uji Asumsi Klasik}

\section{Uji Normalitas}

Dalam mencaritau variabel dependen dan variabel independen apakah 
mempunyai atau mendekati distribusi normal".

\section{Uji Multikolinieritas}

menguji adakah korelasinya antara Variabel dependent dan variabel independent VIF $<10$.

\section{Uji Heteroskedastisitas}

Dipakai dalam mencaritau ketidaksamaan varians tiap variabel,"Sugiyono (2013 : 124).

\section{Rancangan Pengujian} Hipotesis

a. Uji t ( Parsial)

Dipakai dalam mencaritau variabel apakah yang mempengaruhi.Pengk ajian pengiklanan kepada penciptaan penghasilan dengan cara (partial)

b .Koefisien Determinasi Untuk mengetahui persen nilai penciptaan penghasilan sebagai variabel terikatnya

c.AnalisRegresiBerganda Dipakai dalam mencaritau adakah pengaruh di kedua variable "Gozali (2006)"

4. Uji F ( Simultan)

Dipakai dalam pengujian untuk menguji Pengkajian, Pengiklanan, terhadap penciptaan penghasilan secara bersama-sama.

\begin{tabular}{|c|c|c|c|}
\hline No & $\begin{array}{c}\text { "r } \\
\text { Hitusg" }\end{array}$ & $\begin{array}{l}\text { "r } \\
\text { TabcF" }\end{array}$ & Simpulan \\
\hline 1 & 0.836 & 0,163 & "Valid" \\
\hline 2 & 0.831 & 0,163 & "Valid" \\
\hline 3 & 0.767 & 0,163 & "Valid" \\
\hline 4 & 0.814 & 0,163 & "Valid" \\
\hline 5 & 0.841 & 0,163 & "Valid" \\
\hline 6 & 0.858 & 0,163 & "Valid" \\
\hline 7 & 0.801 & 0,163 & "Valid" \\
\hline 8 & 0.801 & 0,163 & "Valid" \\
\hline 9 & 0.852 & 0,163 & "Valid" \\
\hline 10 & 0.807 & 0,163 & "Valid" \\
\hline 11 & 0.858 & 0,163 & "Valid" \\
\hline 12 & 0791 & 0,163 & "Valid" \\
\hline
\end{tabular}

HASIL SERTA PEMBAHASAN

\section{A. Hasil Uji Instrumen Penelitian 1. Hasil Uji Validitas}

"Sugiyono (2009:172) dipakai dalam mencaritau absah tidaknya tiap variable, mengacu kepada $\mathrm{r}_{\text {tabel }}$ productmoment, $d f=$ ( $\alpha, \quad n-2)$. Responden dari sejumlah113 akan dihasilkan $r_{\text {tabel }}=0,163$ signifikansinya $<$ 0,05. Disimpulkan absah dengan mengacu " $r_{\text {hitung }}>r_{\text {tabel. }}$ " 
a.Uji Validitas Variable

\begin{tabular}{|c|c|c|c|}
\hline No & $\begin{array}{c}\text { "r } \\
\text { Hatang" }\end{array}$ & $\begin{array}{l}\text { "r } \\
\text { Taber }\end{array}$ & Simpulan \\
\hline 1 & 0.760 & 0,163 & "Valid" \\
\hline 2 & 0.815 & 0,163 & "Valid" \\
\hline 3 & 0.875 & 0,163 & "Valid" \\
\hline 4 & 0,916 & 0,163 & "Valid" \\
\hline 5 & 0,871 & 0,163 & "Valid" \\
\hline 6 & 0.893 & 0,163 & "Valid" \\
\hline 7 & 0.921 & 0,163 & "Valid" \\
\hline 8 & 0.876 & 0,163 & "Valid" \\
\hline 9 & 0.867 & 0,163 & "Valid" \\
\hline 10 & 0.863 & 0,163 & "Valid" \\
\hline 11 & 0.900 & 0,163 & "Valid" \\
\hline 12 & 0.857 & 0,163 & "Valid" \\
\hline & & & \\
\hline
\end{tabular}

Pengkajian $\left(\mathbf{X}_{1}\right)$

\section{Pengiklanan $\left(\mathbf{X}_{2}\right.$}

\section{Penciptaan Penghasilan(Y)}

\begin{tabular}{|c|c|c|c|}
\hline No & $\mathbf{r}$ Hiturs & $\mathbf{r}$ Tabel & Ket. Butir \\
\hline 1 & 0.874 & 0,163 & "Valid" \\
\hline 2 & 0.825 & 0,163 & "Valid" \\
\hline 3 & 0.898 & 0,163 & "Valid" \\
\hline 4 & 0.901 & 0,163 & "Valid" \\
\hline 5 & 0.926 & 0,163 & "Valid" \\
\hline 6 & 0.900 & 0,163 & "Valid" \\
\hline 7 & 0.897 & 0,163 & "Valid" \\
\hline 8 & 0.893 & 0,163 & "Valid" \\
\hline 9 & 0.894 & 0,163 & "Valid" \\
\hline 10 & 0.872 & 0,163 & "Valid" \\
\hline 11 & 0.783 & 0,163 & "Valid" \\
\hline 12 & 0.840 & 0,163 & "Valid" \\
\hline
\end{tabular}

\section{b.Hasil Uji Reliabilitas}

Penguraian Gozali (2006) Akan disimpukanreliabell dengan alasan puya nilai CronbachAlphanya yang melebihi 060. Setelah dilakukan penghitungan didapatkan hasil nilai Conbrachnya melebihi 0,60 yaitu 0,782 , serta didapatkan $\mathrm{r}$

tabel 0,163dan 5 persen signifikan. Kesimpulannya item-item tersebut bersifat reliable. Dengan interpretasinya yang kuat hingga variable ini bisa dijadikan alat pengukur

\section{Hasil Uji Asumsi Klasik}
a. Hasil
Uji 


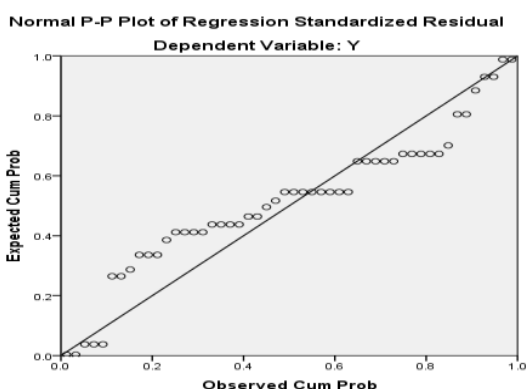

Dapat dilihat dari gambaran di atas bahwa seebaran titik saling mendekati dan titik ini terbentuk disekeliling garis lurus diagonal, dapatlah diartikan bahwa regresi menghasilkan nilainiai residu yang normal. Selanjutnya dalam mencaritau kenormalan distribusi datanya (nilai signifikan harus melebihi $0,05)$ yang harus dilakukan dengan pengujian One Sample Kolmogrov Smirnov dipakai untuk mencaritau residu disribusinya dalam keadaan normal ataukah sebaliknya (tidak normal).

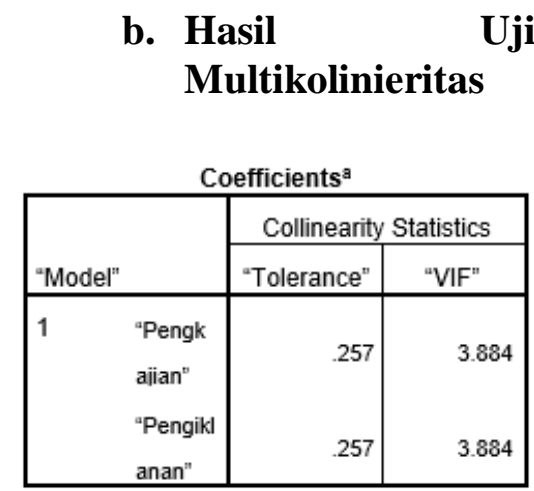

Dari keluaran data didapatkan bahwa gejala-gejala terjadinya korellasi tidak ada dengan mengacu pada "VIF nilainya kurang dari sepuluh $(<10)$ serta didapatkannya nilai toleransi melebihi $010 \quad(>\quad 0,10)$ Kesimpulannya tidakadanya korelasi pada masing-masing variabel bebasnya.

\section{c. Hasil \\ Uji \\ Heteroskedastisitas}

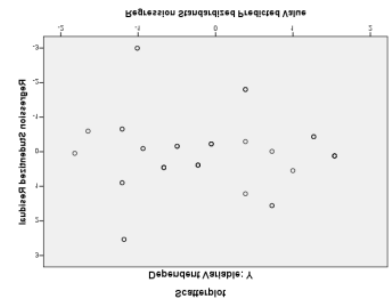

Disimpulkan permasalahan heterokedastisitas tidak ada di dalam regresi ini, titik-titik ini membentuk pola yang tidak jelas, serta titik-titik ini tersebut melakukan penyebaran pada bagian atas dan bagian bawah angka 0 sumbu $\mathrm{Y}$, hal tersebut

\section{B.Analisis Verifikatif}

\section{Hasil Pengaruh secara Partial}

Hasil Pengujian Hipotesis Pengkajian (X) terhadap Penciptaan Penghasilan (Y)

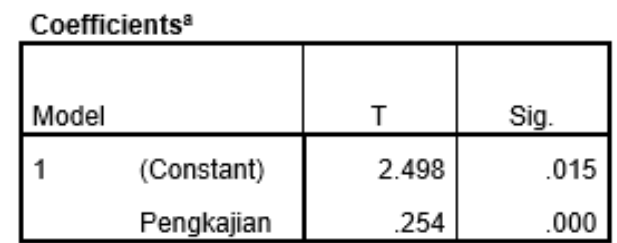

a. Dependent Variable: Y̌spenciptaaan "penghasilan" Berdasarkan output diperoleh hasilnya sebagai berikut: Hasil uji parsial menunjukkan variabel Pengkajian memiliki pengaruh yang baik kepada peciptaan penghasilan dilihat dari nilai $t$ hitung untuk variabel Pengkajian (2.294) > nilai $t_{\text {tabell }}$ (1.980) dan dihasilkan untuk variabel Pengkajian memiliki pengaruh sangat berarti kepada peciptaan penghasilan. 
Kesimpulannya adalah Pengkajian mepunyai pengaruh kepada peciptaan penghasilan.

\section{Hasil Koefisien Determinasi Square) $/ \mathrm{X}_{1}$ terhadap $\mathrm{Y}$.}

\begin{tabular}{|c|c|c|c|c|}
\hline \multicolumn{5}{|c|}{ Model Summary ${ }^{D}$} \\
\hline "Model & & & "Adjusted R & Std. Error of the \\
\hline$n$ & "R" & "R Square" & Square" & Estimate \\
\hline 1 & $8.880^{\mathrm{a}}$ & .786 & .780 & .28013 \\
\hline
\end{tabular}

Hasil keluaran yaitu $\mathrm{R}$ square 0,786 diubah menjadi persen yaitu $78,6 \%$. Adapun $78.6 \%$ besarannya variabel Pengkajian kepada penciptaan penghasilan. Variabel bebas lainnya yang memberikan pengaruh tapintidak dilakukan penelitian yaitu $21,4 \%$.

\section{Hasil Analisis Regresi / $X_{1}$ terhadap Y}

Berdasarkan output/keluaran pada tabel

\begin{tabular}{|c|c|c|c|}
\hline \multirow{2}{*}{\multicolumn{2}{|c|}{ "Model" }} & \multicolumn{2}{|c|}{ Unstandardized Coefficients } \\
\hline & & B & Std. Error \\
\hline \multirow[t]{2}{*}{1} & ${ }^{a}(\text { Constant })^{x}$ & 6.189 & .243 \\
\hline & "Pengkajian" & .254 & .110 \\
\hline
\end{tabular}

hasil persamaan regresinya: $\hat{Y}=$ $6,189+0,254 \mathrm{X}_{1}$ Penjelasannya ialah : Konstanta besarannya 6,189 menyatakan bahwa tanpa variable Pengkajian, peciptaan penghasilan mempunyai nilai yang besar 6,189 Nilai coefficents yaitu 6,189 yang berarti andaikan Pengkajian meningkat sebesar 1satuan akan berdampak peningkatan sebanyak 0,254 .

Pada persamaan tersebut dapat dilihat bahwa Pengkajian memiliki kemampuan mempengaruhi penciptaan penghasilan. Kesimpulannya adalah Pengkajian berpengaruh kepada penciptaan penghasilan.

\section{Hasil Pengujian Hipotesis Pengiklanan $\left(\mathbf{X}_{2}\right)$ penciptaan "penghasilan".(Y) \\ terhadap}

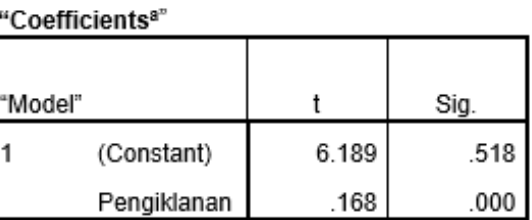

Berdasarkan output pada tabel hasil persamaan regresinya : $\hat{Y}=6,189+$ $0,168 \quad \mathrm{X}_{2}$ Penjelasannya yaitu : Konstanta besarannya 0,168 menyatakan bahwasanya tanpa variabl Pengiklanan, peciptaan penghasilan punya nilai yang besaran nilai koefisien 6,189 yaitu 6,189 yang berarti andaikan Pengiklanan meningkat sebesar 1satuan akan berdampak peningkatan sebanyak 0,168. Pada persamaan tersebut dapat dilihat bahwa Pengiklanan memiliki kemampuan mempengaruhi penciptaan penghasilan. Kesimpulannya ialah pengiklanan berpengaruh kepada penciptaan penghasilan.

Hasil Koefisien Determinasi (RSquare) / $\mathrm{X}_{2}$ terhadap Y.

\begin{tabular}{|l|r|r|r|r|}
\hline Model Summary \\
\hline Model & \multicolumn{1}{c|}{$R$} & R Square & \multicolumn{1}{c|}{$\begin{array}{c}\text { Sdjusted R } \\
\text { Square }\end{array}$} & $\begin{array}{c}\text { Std. Error of the } \\
\text { Estimate }\end{array}$ \\
\hline 1 & .889 & .790 & .784 & .33207 \\
\hline
\end{tabular}

Hasil yaitu R square 0,790 dan diubah menjadi persen yaitu 79,0\%. Artinya bahwa presentase pengaruh Pengkajian terhadap peciptaan penghasilan besarannya $79,0 \%$ sisanya merupakan pengaruh dari variabel bebas lainnya besarannya yaitu21,6\% tetapi tidak dilakukan penelitian. 
Hasil Analisis Regresi / $\mathbf{X}_{2}$ terhadap Y

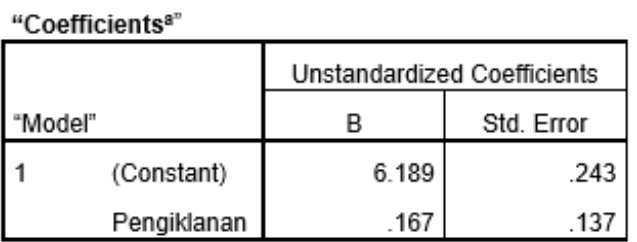

Berdasarkan output persamaan regresi di penelitian ialah: $\hat{Y}=6,189+0,167 \mathrm{X}_{2}$ Penjelasannya : Konstanta

yang besarannya 6,189 menyatakan bahwa tanpa variabel Pengiklanan, penciptaan penghasilan mempunyai nilai yaitu 6,189. Nilaicoefficents yang besarannya 0,167 . Artinya jika Pengiklanan naiknya satu satuan maka Penciptaan penghasilan akan naik juga 0,167. Pada persamaan tersebut dapat dilihat bahwa Penciptaan penghasilan memiliki kemampuan mempengaruhi Penciptaan penghasilan. Hal ini menunjukkan bahwasanya Penciptaan penghasilan dapat dipengaruhi oleh Pengiklanan.

\section{Hasil Uji F Pengujian Pengaruh Pengkajian, Pengiklananterhadap Penciptaan Penghasilan.}

ANOVA $^{\mathrm{a}}$
\begin{tabular}{|ll|r|c|}
\hline Model & & $\mathrm{F}$ & Sig \\
\hline 1 & $\begin{array}{l}\text { Regression } \\
\text { Residual } \\
\text { Total }\end{array}$ & 22.147 & 000 \\
\hline
\end{tabular}

Berdasarkan output table nilai (22.147) lebih besar dibandingkan dengan nilai $F_{\text {tabel }} \quad(2,79) \quad$ adapun "signifikan". $\alpha(0,000) \quad$ yang tidak melebihi alpha 5persen $(0,05)$. Kesimpulannya didapatkan bahwa Hipotesis 0 tidak diterima serta Hipotesis a tidak ditolak, maka dengan cara simultan Pengkajian,pengiklanan memiliki pengaruh yang sangat berarti kepada penciptaan penghasilan.

Hasil Koefisien Determinasi ( $R$ Square) $X_{1}, X_{2}$, terhadap $Y$

Model Summary ${ }^{\circ}$

\begin{tabular}{|l|r|r|r|r|}
\hline Model & \multicolumn{1}{|c|}{$R$} & R Square & \multicolumn{1}{c|}{$\begin{array}{c}\text { Adusted R } \\
\text { Square }\end{array}$} & $\begin{array}{c}\text { Sta. Error of the } \\
\text { Estimate }\end{array}$ \\
\hline 1 & .964 & .928 & .925 & .22378 \\
\hline
\end{tabular}

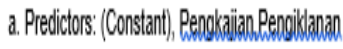

b. Dependent Variable: Penciplaan "Penghasialan"

Hasil yaitu Rsquare 0,928 dan diubah menjadi persen yaitu 92,8 persen. Artinya bahwa presentase pengaruh Pengkajian,Pengiklanan terhadap peciptaan penghasilan besarannya 92,8 persen sisanya merupakan pengaruh dari variabel bebas lainnya besarannya yaitu 8,2 persen tetapi tidak dilakukan

Hasil Analisis Regresi / $\mathbf{X}_{1}, \mathbf{X}_{2}$ terhadap Y

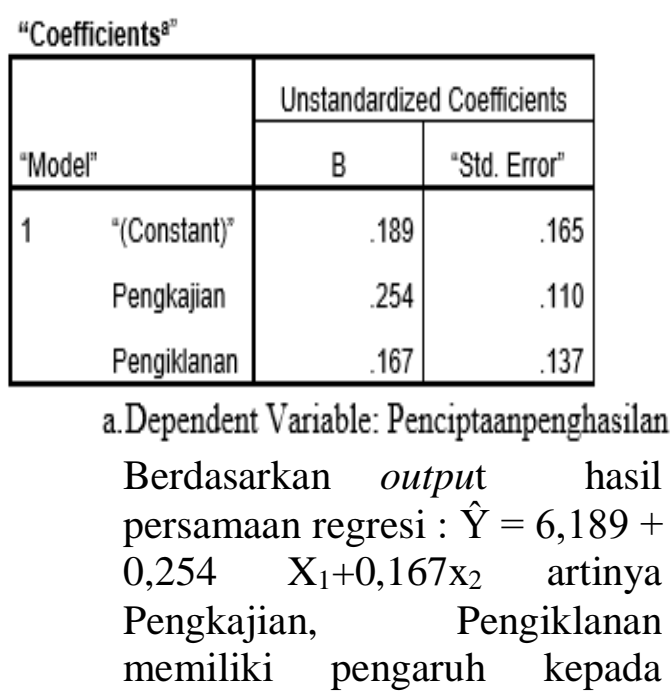




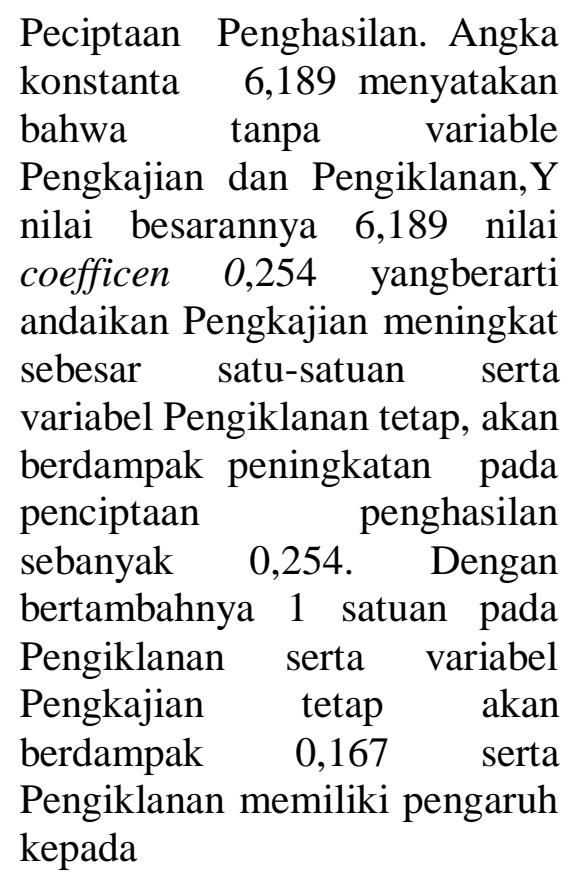

\section{PEMBAHASAN}

Merujuk pada hasil yang diperoleh dari deskripsi penganalisaan dilakukanlah pembahasan berdasar frekuensi pemili han opsi pada setiap pernyataan pada varaiabel independendan dependen (variabel Pengkajian, pengiklanan dan Penciptaan Penghasilan ) yang diajukan kepada responden penelitian sebagai berikut:

\section{VariablePengkajian $\left(X_{1}\right)$}

Hasil Hipotesis disimpulkan Pengkajian mempunyai pengaruh yang sangat berarti kepada penciptaanpenghasilan. Pembahasan pada peneitian ini memperkuat pendapat beberapa peneliti yang lain. Bisa disimpukan bahwa Pengkajian memiliki pengaruh baik yang sangat berarti kepada penciptaan penghasilan

\section{Variable Pengiklanan $\left(\mathbf{X}_{2}\right)$}

Hasil Hipotesis disimpulkan Pengiklanan mempunyai pengaruh yang sangat berarti kepada penciptaan penghasilan. Pembahasan pada penelitian ini memperkuat pendapat beberapa peneliti yang lain. bisa disimpulkan bahwa Pengiklanan memiliki pengaruh baik yang sangat berarti kepada penciptaan penghasilan

\section{VariablePengkajian ( $\mathrm{x} 1)$ dan Penciptaan Penghasilan $\left(\mathrm{x}_{2}\right)$}

Hasil hipotesis diperoleh kesimpulan bahwa Pengkajian dan pengiklanan memiliki pengaruh yang sangat berarti kepada penciptaan penghasilan. Di pembahasan ini yang bisa disimpulkan yaitu Pengkajian dan pengiklanan bersama-sama memiliki pengaruh baik yang sangat berarti kepada penciptaanpenghasilan.

\section{KESIMPULAN DAN SARAN}

\section{A. Kesimpulan}

1.Pengkajian mempunyai pengaruh yang sangat berarti kepada penciptaan penghasilan. Besaran berpengaruhnya dari Pengkajian yaitu 78,6 persen . besaran yang mempengaruhi di variable bebas yang lainnya yang tidak dlakukan penelitian yaitu 21,4persen. Persamaan regresi linier $\mathrm{Y}=6.189+0,254 \mathrm{X}_{1}$

2.Pengiklanan mempunyai pengaruh yang sangat berarti kepada penciptaan penghasilan. Besaran berpengaruhnya dari Pengiklanan yaitu 79,0 persen . Pengiklanan serta besaran yang mempengaruhi di variabel bebas yang lainnya yang tidak dlakukan penelitian yaitu 21,6 persen..Persamaan regresilinier $\hat{\mathrm{Y}}=$ $6.189+0.928 \mathrm{X}_{2}$. 
3. Pengkajian dan Pengiklanan secara bersama-sama memiliki pengaruh yang sangat berarti kepada penciptaan penghasilan.Besaran pengaruhnya dari Pengkajian serta Pengiklanan yaitu 92,8persen. Serta besaran yang mmpengaruhi berasal dari variabel bebas yang lainnyayang tidak dilakukan penelitian yaitu 8,2 persen. Persamaan regesilinier $\hat{\mathrm{Y}}=6,189+$ $0,254 X_{1}+0,167 X_{2}$

\section{B. Saran}

Bagi Kelurahan Cempaka Putih Ciputat merujuk pada jawaban yang diperoleh kuesioner dalam ketiga variabel didapatkan temuan sebagai berikut:

1. Pengkajian

14responden $(28,6 \%)$ menyatakan ragu- ragu pada subindikator kepercayaan diri untuk mengelola usaha, oleh karena itu disarankan kepada Pimpinan Kelurahan agar bisa lebih terbuka, lebih peka lingkungan, mampu berkomunikasi efektip, membangun teamwork.

2. Pengiklanan14responden (28\%) menyatakan ragu-ragu pada subindikator dukungan dari pihak lain untuk menjadi enterpreuner, maka untuk menyelesaikan perihal ini lebih memperhatikan lagi dukungan positip menjalankan usaha, serta menumbuhkan semangat kerja yang tinggi

3. Penciptaan Penghasilan 29,3 responden $(15 \%)$ menyatakan ragu - ragu pada sub indikator berpikir kreatip serta inovatif di sarankan pada kelurahan Cempaka Putih memberikan perhatian lebih pada idea/ gagasan baru

\section{DAFTAR PUSTAKA}

Hasibuan, Malayu., 2008, ManajemenSumberDayaManusia, Bumi aksara, Jakarta.

Hasibuan, Malayu., 2011, Manajemen: Dasar, Pengertian dan Masalah, Bumi Aksara: Jakarta

Fuad Masud,2004, Survei Diagnosis Organisasional ( konsep\& Aplikasi), Undip

Malthis, R.L Jackson, 2006, Manajemen Sumber Daya Manusia, Edisi 10. Salemba Empat, Jakarta

Pasaribu, V. L. D., \& Jaenanto, J. (2020, January). PENGARUH KUALITAS PELAYANAN TERHADAP TINGKAT KEPUASAN PENYEWA RUANG KANTOR DI PT ISMAWA TRIMITRA GEDUNG GRAHA ISKANDARSYAH PERIODE 2018 JAKARTA SELATAN. In PROCEEDINGS (Vol. 1, No. 1).

Pasaribu, V. L. D., Krisnaldy, K., \& Warasto, H. N. (2020). Pengaruh Gaya Kepemimpinan, Disiplin Kerja Dan Kompensasi Terhadap Kinerja Pegawai (Studi kasus kelurahan Pisangan Ciputat). Jurnal Disrupsi Bisnis: Jurnal Ilmiah Prodi Manajemen, Fakultas Ekonomi, Universitas Pamulang, 3(1).

Siagian, Sondang, 2013, Perilaku Organisasi, Salemba Empat, Jakarta

Sugiyono, 2013, StatistikauntukPenelitian, Edisi VI, Alfabeta, Bandung.

(2012) Metode Penelitian Kuantitatif, Kualitatif , Alfabeta, Bandung 


\section{(2011) Metode Penelitian}

Kuantitatif, Kualitatif dan $R \& D$ cetakan ke sebelas,,Alfabeta, Bandung.

Suharto dan Cahyo, 2006, PengaruhBudayaOrganisasi Sondong.Vol 15. Erlangga. Jakarta.

Suharto \& Cahyono, Budi. 2011, ,KepemimpinandanMotivasiTerhadapK inerjaSumberDayaManusiadiSekretari atDPRDprovinsiJawaTengah, Jurnal Riset Bisnis Indonesia Vol. 1 No.1: p.13-30.

Sumarsono, Sonny, 2013, MetodeRisetSumberDayaManusia, STIE YKPN Yogyakarta.

Suranta, 2006, Manajemen Sumber Daya Manusia Vol 2. JRBI, Yogyakarta.

Surat Keputusan Badan Administrasi Kepegawaian Negara no 27 / KEP/ 197

Toha Miftah, 2009, Kepemimpinan, Salemba Empat, Jakarta .

Waridin da nBambang Guritno, 2009, Manajemen Pemerintahan, Pustaka Utama, Jakarta .

Wirawan, 2007, Budaya dan iklimorganisasi, Salemba Empat, Jakarta. 